\section{Coordination is the key for new AIDS research programme}

Paris

ON the eve of World AIDS Day, the French research and technology minister, Hubert Curien, unveiled details of a new pluridisciplinary programme to back AIDs research. Criticized earlier in the year for a lack of positive action and for underfunding (see Nature 333, 103; 1988 ) Curien says money is no longer an issue. The new programme has a budget of FF 150 million ( $£ 14.19$ million) but, he says, "if researchers say they need more money, I have the assurance of the minister for finance and of the Prime Minister that extra funds will be available' - a promise that won a smile from Luc Montagnier, author of the earlier attack.

The emphasis of the programme is on national and international coordination. All AIDS research now comes under the umbrella of a new AIDS agency, headed by professor Jean-Paul Lévy and advised by a scientific advisory council and a series of specialist panels.

The budgets available for basic research represent a doubling of last year's levels. The programme also includes, for the first time in France, a budget (FF3 million) for sociology research on AIDS and FF10 million for research into prevention.

The inclusion of a human sciences budget reflects a new awareness in political circles that there is no hope of a cure or a vaccine in the immediate future. Meanwhile, little is known of the behaviour of populations at risk nor of the projected socio-economic effects of AIDS. As change of behaviour is the only effective prophylactic likely to be available fo some time, says Curien, it is essential that information campaigns are better targeted. One of the chief responsibilities of the new agency will be to encourage

\section{Washington AIDS Day}

LAST Thursday, 1 December, was World AIDS Day, sponsored by the World Health Organization (WHO) to focus attention on the global effort to stop AIDS. More than 100 countries put on special activities intended to increase awareness of AIDS and to discuss how to combat the epidemic.

World AIDS Day saw the number of reported AIDS cases rise to 129,385 , a little over 60 per cent of them in the United States. But WHO officials fear that the real number may be twice as high, given the lack of accurate statistics from Africa. Information campaigns were launched in 39 African countries, where those most at risk of AIDS in Africa are young urban workers who make the biggest contribution to their countries' economies.

Lisa Perlman researchers "on the fringes of AIDS research" - sociologists, sexologists, and epidemiologists.

To ensure that the results of research they percolate rapidly to the public, the agency will organize two annual national symposia, regular meetings on specific topics and the publication of a threemonthly information bulletin. Regular exchanges and joint projects with foreign laboratories will also be reinforced. Since last year, a formal programme of cooperation has existed with West German laboratories, while the UK Medical Research Council has been collaborating with French counterparts. An Anglo-French clinical trial of AZT has just started. While the will to stimulate research is clear in government's programme, it will nevertheless be constrained by a shortage of qualified researchers in some areas.

Peter Coles are shared between laboratories and that

\section{London}

AT least 10,000 new cases of AIDS are bound to be diagnosed in England and Wales between 1988 and 1992, according to the predictions of an expert group published* last week on the eve of World AIDS Day, 1 December. While considerable uncertainties prevent any very definite predictions, the group is certain that the past exponential growth in cases will not be continued over the next few years. But, it concludes, "it would be a gross error to regard even the lower predictions as grounds for complacency".

Continued exponential growth would predict around 10,000 new cases in 1992 alone. Instead, the group estimates there will be only $25-30$ per cent of that number. For the basis of planning, a figure of 3,600 is recommended. In fact, there are likely to be some 20 per cent more cases that are not reported; the group recommends an urgent investigation of the extent of underreporting, which could be as great as 40 per cent.

The group, chaired by Oxford statistician Sir David Cox, was asked by the Ministry of Health to predict the numbers of HIV-infected individuals, and AIDS cases and deaths over the next 2--5 years as an aid to health-care planning. One major problem it faced is the lack of reliable figures on the number of people currently infected with HIV, from whom almost all the new cases of AIDS over the next five years will be drawn. The attention drawn to this problem in the report was one of

Short-term prediction of HIV infection and AIDS in Englan and Wales (HMSO, f6.50).
Condoms condemned

Paris

An influential French consumer magazine has told readers that only 6 of 41 brands of comdom tested would provide adequate protection. Following the publication in $\mathbf{5 0}$ Million de Consommateurs of tests out by the national consumer institute (INC), the French Secretary of State for consumer affairs, Veronique Neiertz, ordered five brands of condom to be withdrawn.

According to Health Department statistics, only 9 per cent of couples in France use condoms, compared with $\mathbf{5 0}$ per cent in Canada and 68 per cent in Japan. Yet the Health Minister, Claude Evin, sees wider acceptance of the condom as the most effective means available to reduce sexual transmission of the AIDS virus.

The INC report subjected condoms to two tests of elasticity - inflation and elongation - and a test of porosity. Fourteen of the brands were judged to have failed the porosity test. The aim of the INC article, according to its authors, was to enable the French public to "choose the right.

\title{
AIDS predictions until 1992
}

the factors that influenced the recent government decision to instigate involuntary and anonymous screening of blood samples for HIV antibodies as soon as the Medical Research Council has drawn up plans (see page 413 of last week's issue).

In the absence of direct information, three different methods of estimating prevelance were used and all suggest that between 20,000 and 50,000 people were infected with HIV by the end of 1987 , of whom 6,000-17,000 are heterosexuals. Although this provides the potential for considerable further heterosexual spread, Cox and his colleagues assume, for their predictions, that there will not be a large increase in the number of heterosexual cases of AIDS in the next few years. They also assume that the changes in behaviour among homosexuals that have stopped the exponential growth in AIDS cases will continue into the future.

The report recommends that its predictions should be updated annually by the Communicable Disease Surveillance Centre, and the Ministry of Health has agreed - without immediately offering any extra resources. But the ministry has delayed any specific response to most other recommendations. These include an urgent need for the study of sexual behaviour in high-risk groups as well as investigation of factors affecting HIV transmission between intravenous drug users. Several suggestions for future epidemiological studies of infection may re-emerge as part of the Medical Research Council's plan of action.

Peter Newmark 